\title{
OS IMPACTOS FINANCEIROS CAUSADOS PELA PANDEMIA DA COVID-19 NAS MICRO E PEQUENAS EMPRESAS E A ATUAÇÃO DA CONTABILIDADE COMO INSTRUMENTO DE GESTÃO
}

\section{ARTIGO ORIGINAL}

ALMEIDA, Rosivane Rolim de ${ }^{1}$, LIBÓRIO, Yandra Beatriz Rolim², SOUZA JÚNIOR, Márcio Fábio Veras de ${ }^{3}$, NUNES, Fabiane Guedes ${ }^{4}$, ROBERTO, José Carlos Alves ${ }^{5}$, SERRA, Meg Rocha da Cunha6 ${ }^{6}$, LOPES, Nelânia Ferreira7

ALMEIDA, Rosivane Rolim de. Et al. Os impactos financeiros causados pela pandemia da COVID-19 nas micro e pequenas empresas e a atuação da contabilidade como instrumento de gestão. Revista Científica Multidisciplinar Núcleo do Conhecimento. Ano. 06, Ed. 11, Vol. 12, pp. 49-70. Novembro 2021. ISSN: 2448-0959, Link de acesso: https://www.nucleodoconhecimento.com.br/contabilidade/impactos-financeiros, DOI: 10.32749/nucleodoconhecimento.com.br/contabilidade/impactos-financeiros

\section{RESUMO}

A presente pesquisa é definida como uma revisão bibliográfica que discorre sobre os impactos financeiros nas micro e pequenas empresas durante a pandemia provocada pela COVID-19. Neste contexto, a maior preocupação dos gestores destes tipos de empresas pode ser explicada pela insuficiência de capital, pois a maioria delas enfrentam problemas relacionados ao gerenciamento das questões

\footnotetext{
${ }^{1}$ Graduanda do curso de Contabilidade.

${ }^{2}$ Graduando do curso de Contabilidade.

${ }^{3}$ Graduando do curso de contabilidade.

${ }^{4}$ Graduando do curso de contabilidade.

${ }^{5}$ Orientador. Mestre em Engenharia de produção, Especialista Logística empresarial e Graduado em Administração com Ênfase em Marketing.

${ }^{6}$ Orientadora. Mestra em Engenharia de Processos Industriais pela UFPA, especialista em Controladoria e Auditoria Contábil pelo Ciesa (2020), Graduada em Ciências Contábeis pelo Centro Universitário do Norte (2010). Graduada em Ciências Econômicas pelo Centro Universitário do Norte (2006).

${ }^{7}$ Especialista em Auditoria Contábil, Financeira e Tributaria e Graduada em Ciências Contábeis.
}

RC: 101951

Disponível em: https://www.nucleodoconhecimento.com.br/contabilidade/impactosfinanceiros 
operacionais e financeiras. Diante disto, o presente artigo, tem como questão norteadora: Como a contabilidade pode auxiliar na gestão financeira das micro e pequenas empresas perante a crise provocada pela pandemia da COVID-19? Tem como objetivo geral demonstrar os tipos de ferramentas contábeis que podem contribuir na gestão financeira das micro e pequenas empresas. Com relação à metodologia foram adotados métodos bibliográficos. Como resultados, constatou-se que a contabilidade tem ferramentas úteis voltadas ao processo gerencial e financeiro, podendo auxiliar no controle de custos e despesas, a partir do orçamento e do fluxo de caixa.

Palavras-chave: Ferramentas contábeis, Impactos financeiros, Crise econômica provocada pela pandemia da COVID-19, Empresas de pequeno porte.

\section{INTRODUÇÃO}

A pandemia provocada pela COVID-19 evoluiu rapidamente, causando um impacto trágico na vida humana, o que gerou maior volatilidade nos mercados de capitais globais. Muitas empresas foram forçadas a lidar com o impacto em seus negócios, incluindo implicações contábeis e de relatórios financeiros. A evolução desse contexto afetou toda a cadeia na área de negócios, resultando no fechamento de empresas e restrições impostas pelo Estado às entidades. Estas, por sua vez, foram forçadas a mudar o método de operação, muitas fecharam temporariamente e adotaram o home office.

Segundo Santos; Dorow e Beuren (2016) a gestão das consequências financeiras mediante a crise atual, causada pela COVID-19, é importante para que estas obtenham uma área financeira eficiente, com intuito de minimizar ao máximo despesas que possam interferir na micro e pequena empresa, sendo possível sanar os danos acometidos na economia do negócio.

Baseando-se no cenário econômico atual, impulsionado pela pandemia provocada pela COVID-19, surgiu a seguinte questão: Como a contabilidade pode auxiliar na 
gestão financeira das micro e pequenas empresas perante a crise provocada pela pandemia da COVID-19?

Diante desse contexto, tem-se uma maior preocupação com as micro e pequenas empresas, pois tais organizações não possuem capital suficiente para que seja fundado um setor exclusivo para a o gerenciamento das questões financeiras. Para Jacomete (2019), essas empresas são importantes para o país porque ajudam a aumentar o emprego e o desenvolvimento econômico.

O Instituto Brasileiro de Geografia e Estatística (2020) apresentou dados que afirmam que, atualmente, as micro e pequenas empresas representam $30 \%$ do PIB brasileiro, o que mostra a significância do crescimento constante dessa modalidade de pequenos negócios.

Neste contexto, demonstrar os tipos de ferramentas contábeis que podem contribuir na gestão financeira das micro e pequenas empresas. Como metodologia, foram adotados métodos bibliográficos.

\section{FUNDAMENTAÇÃO TEÓRICA}

Segundo Marconi e Lakatos (2015), a fundamentação teórica é a etapa do artigo que inclui as revisões realizadas com base nos estudos analisados. Essa etapa parte da descrição das informações selecionadas entre os principais autores escolhidos para compor os tópicos e subtópicos do referencial teórico.

\subsection{CONCEITOS DE MICRO E PEQUENAS EMPRESAS}

De acordo com a Lei Complementar № 123/2006, as micro e pequenas empresas são classificadas como organizações que possuem um determinado valor de faturamento por ano, em relação aos ganhos brutos, que são independentes da despesa que cada empresa possui (BRASIL, 2006). 
Entende-se como lucro o valor que a organização possui após realizar os pagamentos das despesas, como o salário dos colaboradores, pagamento de fornecedor, imposto e afins. Sendo assim, Pessôa; Costa e Maccari (2016), afirmam que as micro empresas são organizações de sociedades simples, individuais ou com atributos limitados, com o ganho por ano de até $R \$ 360.000,00$. Já as pequenas empresas são definidas como as organizações simples, individuais, assumindo, também, responsabilidades limitadas, porém, o faturamento por ano é maior do que $\mathrm{R} \$ 360.000,00$ (trezentos e sessenta mil reais) e igual ou inferior a $\mathrm{R} \$ 3.600 .000,00$.

Em relação à quantidade de funcionários que as micro e pequenas empresas podem ter, o Sebrae (2020) as classifica como: microempresas: possuem até nove colaboradores nas áreas de prestação de serviço e comércios, ou, então, podem contar com, no máximo, dezenove nas áreas industriais e de construções. Quanto às pequenas empresas: há o emprego de nove a dezenove colaboradores nas áreas de prestação de serviço e comércios ou, então, podem contar com, no máximo, vinte a noventa e nove nas áreas industriais e de construções (SEBRAE, 2020).

Segundo Silva (2021), a microempresa apresenta-se como uma pequena empresa que vende bens e/ou serviços para uma área local ou um mercado local. Em geral, emprega menos de 10 pessoas e é geograficamente restrita. Normalmente, uma microempresa começa com alguma forma de financiamento, conhecida como microcrédito ou microfinanciamento.

A pesquisa realizada por Jesus e Marinho (2019) aponta que as microempresas dizem respeito, geralmente, a uma marca registrada de um país e economia em desenvolvimento. Assim sendo, há uma escassez de empregos no setor formal e as microempresas buscam preencher essa lacuna. Eles ajudam a economia não apenas com a criação de novos empregos, mas também reduzem os custos de produção, aumentam o poder de compra e, ainda, proporcionam uma maior conveniência. 


\subsubsection{A IMPORTÂNCIA DAS MICRO E PEQUENAS EMPRESAS PARA A ECONOMIA BRASILEIRA}

De acordo com Jacomete (2019), as micro e pequenas empresas são importantes porque ajudam a aumentar o emprego e o desenvolvimento econômico. Além disso, melhoram o crescimento do país, bem como aumentam o crescimento urbano e rural. O intuito dessas empresas é ajudar o governo a expandir as infraestruturas e as indústrias de manufatura, mitigando questões como poluição, favelas, pobreza e outros atos de desenvolvimento. As empresas manufatureiras de pequena escala desempenham um papel muito importante no desenvolvimento econômico à nível nacional.

Segundo dados do IBGE (2011) (Instituto Brasileiro de Geografia e Estatística), atualmente, as micro e pequenas empresas representam $30 \%$ do PIB brasileiro, o que mostra a grande significância do crescimento constante dessa modalidade de pequenos negócios.

Entre as diversas atividades que as micro e pequenas empresas desempenham, o comércio e serviço correspondem a cerca de $23 \%$ do total do PIB (IBGE, 2011). Essa crescente estatística pode ser explicada pelo fato de que essas empresas estão localizadas em diversas regiões de cada Município. Em todos os bairros de cada cidade há um micro empreendimento.

Bateria e Manolescu (2017) apontam que na área do comércio, as micro e pequenas empresas correspondem a 53\% do PIB. Quanto ao setor de construções civis, elas representam 55\% do PIB. Os autores ainda afirmam que há um aumento constante da participação dessas sociedades no PIB. Além disso, a geração de empregos também é muito significativa para a estatística nacional.

As micro e pequenas empresas contribuem para que $50 \%$ da taxa de empregabilidade seja formada. Dados referentes às micro e pequenas empresas no 
Brasil, quanto à quantidade à nível nacional e regional, foram apresentados pelo Sebrae (2020).

O número de empresas por UF no Brasil, segundo o relatório realizado pelo Sebrae no último semestre de 2020, demonstrou que o total de micro e pequenas empresas no país era de 7.482.833, além disso é interpretado que São Paulo é capital brasileira com maior índice de empresas de pequeno porte, seguida de Minas Gerais (SEBRAE, 2020).

Segundo Rendon (2014), as microempresas visam à criação de empregos em larga escala na economia, separados do setor formal. Elas atingem essa meta com finanças e investimentos muito limitados. Além disto, elas auxiliam no desenvolvimento da economia em geral, tendo o objetivo de inserir as áreas atrasadas no plano de desenvolvimento nacional, promovendo o desenvolvimento regional.

\subsection{CONCEITO DE CONTABILIDADE}

Segundo Araújo (2017), a contabilidade é uma maneira de comunicar a saúde financeira de uma empresa ou organização a todas as partes interessadas. É um setor organizacional de uma empresa e todos os tipos de negócios têm informações básicas que são registradas para realizar esse trabalho. Independentemente da modalidade, a contabilidade é considerada como um conjunto de práticas e ferramentas padronizadas com o objetivo de atender aos processos contábeis aplicados a diversos tipos de negócios.

Para Paulani e Bobika (2020), a contabilidade pode ser considerada uma ferramenta, pois, em uma corporação ou negócio, existem muitas camadas ou tipos de contabilidade. Em empresas e corporações muito grandes, cada uma dessas camadas pode ter seu próprio departamento, composto por múltiplos contadores.

Em pequenas empresas, tudo pode ser trabalho de um contador. Essas especializações incluem impostos, pois todas as empresas têm de pagar impostos.

RC: 101951

Disponível em: https://www.nucleodoconhecimento.com.br/contabilidade/impactosfinanceiros 
Além disso, outra especialização das ferramentas da contabilidade é a folha de pagamento.

Segundo Ribeiro (2017), as empresas precisam bancar os funcionários, mas há algo que é mais importante: precisam pagar impostos sobre a folha de pagamento, previdência social, aposentadoria, compensação do trabalhador e assim por diante. Os contadores da folha de pagamento mantêm todas essas ferramentas em desenvolvimento, assim como as contas a pagar e contas a receber.

Segundo Almeida (2016), o contador não tem nenhum controle sobre o dinheiro, mas garante que cada pequena transação seja registrada. Além disso, uma das funções mais importantes de um contador é desenvolver relatórios para a gerência e executivos. Por isso, é essencial que as atividades da contabilidade sejam realizadas em conjunto aos mecanismos tecnológicos.

\subsection{A PANDEMIA DA COVID 19 NO BRASIL}

Segundo Marcelino; Rezende e Miyaji (2020), a pandemia do COVID-19 (Corona Vírus Disease 19) têm impactado diretamente diversos espectros das atividades humanas, tais como a saúde, educação, meio ambiente e economia. Dentre os mais afetados, o setor econômico, destaca-se pela crescente taxa de desemprego no Brasil, impulsionada pela crise pandêmica, além das consequências nas atividades empresariais.

Os dados do IBGE (2020) reiteram que a taxa de desemprego cresceu cerca de 12\% no primeiro trimestre de 2020 no Brasil. Neste âmbito, relações de negócios previamente firmados e contratos empregatícios têm sido repensadas, bem como as formas de cumprimento de deveres assumidos em contratos de diferentes espécies. Todavia, medidas podem ser tomadas a fim de facilitar as relações contratuais em ambas as partes. 


\subsubsection{AS MEDIDAS PROVISÓRIAS GOVERNAMENTAIS PARA MICRO E PEQUENAS EMPRESAS DURANTE A PANDEMIA}

Segundo Santos e Oliveira (2021), algumas medidas governamentais foram instauradas durante a pandemia para que as empresas não sofressem tanto com a crise econômica. Além disso, essas medidas também visam reduzir o número de desempregos, que se tornou crescente desde o início da pandemia. Leva-se em consideração as medidas de segurança de isolamento social associadas ao medo das pessoas de sair de casa. Assim, foi necessário que fossem tomadas medidas para que evitassem a paralisação total do ramo empresarial.

Dentre as medidas provisórias governamentais tomadas a fim de minimizar danos aos indivíduos, tem-se aquela referente aos conflitos contratuais que a empresa possui. Determinou-se que as negociações da forma de pagamento por ambas as partes por meio da modificação da cláusula preço, ou o adiamento do prazo, eram comuns (SANTOS E OLIVEIRA, 2021).

Essa medida foi concedida a partir da liminar instaurada pela 22 ${ }^{\text {a }}$ Vara Cível do Tribunal de Justiça de São Paulo, que permitiu a diminuição do valor do aluguel de restaurantes em 30\% durante o período de redução das atividades (SILVESTRE, 2020).

Tal medida supracitada tem sido também adotada por empreendedores e lojistas de centros comerciais que necessitam cumprir com os deveres contratuais. Outra parte do empreendimento, entretanto, optou pela suspensão da exigibilidade de cobranças, condicionando os pagamentos a descontos aplicados em diferentes patamares (SQUEFF; D'AQUINO; TARGA, 2021).

Além disso, para as empresas, foi abordada a situação sobre as jornadas de trabalho durante o período de pandemia, visto que muitas foram impactadas. Por isso, foram instituídas as interrupções no trabalho por motivo de força maior, com a compensação das horas trabalhadas posteriormente. 
No que se refere a interromper o contrato de trabalho em casos vigentes, cumpre mencionar que se tornou válida, nesses casos, a continuação dos direitos trabalhistas assegurados, assim como o registro do período de afastamento para efeitos legais. Dessa forma, os funcionários continuaram a deter seus direitos trabalhistas como se o executassem nas dependências da empresa (SILVESTRE, 2020).

Tornou-se viável, também, a negociação via sindicato, chegando-se à solução da redução da jornada de trabalho com salário proporcional. Dessa forma, o empregador expôs menos os seus funcionários ao vírus e, com isso, diminuiu-se o risco de contágio no ambiente de trabalho. Esta medida apresentou-se eficaz, uma vez que, em hipóteses de contágio, o afastamento de 15 (quinze) dias é providenciado pelo empregador, ocasionando despesas maiores (SQUEFF; D'AQUINO; TARGA, 2021).

Uma via alternativa de manter o equilíbrio econômico-financeiro foi a antecipação de férias e banco de horas com o pagamento de $1 / 3$ das férias fornecido pela empresa. Dessa forma, o empregador diminuiu custos e evitou a inadimplência. Esse direito foi concedido ao empresário pela Medida Provisória № 927, ainda tramitando, que dispõe sobre alternativas trabalhistas para o enfrentamento de calamidades públicas e para a preservação de emprego e renda (SILVESTRE, 2020).

\subsection{OS IMPACTOS FINANCEIROS CAUSADO NAS MICRO E PEQUENAS EMPRESAS}

De acordo com Bernardes; Sousa e Lima (2020), apesar das diferenças persistentes entre os países, a crise provocada pela COVID-19 aumentou o dinamismo no cenário do comércio eletrônico entre os países e expandiu o escopo do comércio eletrônico, afetando, sobretudo, novas empresas, segmentos de consumo (por exemplo, idosos) e produtos (por exemplo, mantimentos). Esse contexto forneceu às empresas um novo modo de trabalho, o virtual, de modo que muitas delas adotaram o método de trabalho home office, cujos funcionários têm a possibilidade de 
trabalhar de casa, o que diminuiu o impacto negativo que as organizações sofreram com a pandemia.

As referidas medidas governamentais, para conterem o contágio pelo vírus da COVID-19, fomentaram o isolamento social, sendo que este acarretou a suspensão de atividades, principalmente em setores econômicos, como prestação de serviços e comércio varejista, representados, principalmente, por empresas de porte micro ou pequeno (SEBRAE, 2020). Uma importante dimensão trazida pela pesquisa do Sebrae (2020) diz respeito ao impacto da pandemia no funcionamento das organizações. Evidenciou-se que 39\% dos empreendedores declararam que os seus pequenos negócios não conseguem funcionar sem ser de forma presencial, ou seja, as medidas de restrição impedem que o empreendimento funcione. Em função disto, no âmbito da operação e funcionamento, $43 \%$ ficaram temporariamente fechadas, o que fez com que essas empresas tivessem seus negócios afetados financeiramente.

Ainda na pesquisa feita pelo Sebrae (2020), no que tocava ao endividamento, constatou-se que $41 \%$ dos pequenos negócios possuem dívidas em atraso, o que acarretou maior dificuldade de acesso ao crédito. Desde o começo da crise, 39\% tentaram acessar crédito/empréstimo em banco e, entre estes, os resultados foram os seguintes: apenas 16\% conseguiram o empréstimo, $27 \%$ aguardavam uma resposta e 57\% não conseguiram. Em termos numéricos, entre as 6,7 milhões de empresas que realizaram pedidos de empréstimo, apenas um milhão conseguiu.

Santos; Dorow e Beuren (2016) frisam que o gerenciamento dos impactos financeiros mediante a uma crise econômica é essencial para que as empresas obtenham uma gestão financeira eficiente, para que seja possível minimizar ao máximo despesas que possam interferir na gestão da micro e pequena empresa, sendo possível sanar os danos acometidos na economia do negócio.

Por isso, é importante que, nesse gerenciamento, haja a prevenção de possíveis ocorrências que possam agravar a crise. 


\subsection{ATUAÇÃO DA CONTABILIDADE PARA GESTÃO DAS MICRO E PEQUENAS EMPRESAS}

Como mostrado no estudo de Frey e Frey (2015), que resultou na diferença da implementação de serviços contábeis em uma empresa, constatou-se que os registros informam os proprietários do lucro ou perda real, assim como apresenta-se dados sobre a renda recebida de vendas e as despesas. Ou seja, pode-se afirmar que, nesse cenário, a contabilidade exerce uma grande influência na análise financeira da empresa, pois envolve a preparação de informação para os propósitos e objetivos relacionados à interpretação avaliativa das movimentações financeiras, bem como aos registros simples de dados precisos. Nascimento e Gomes (2020) mostraram que a ausência de ferramentas contábeis na gestão de microempresa é um dos fatores principais para o fechamento de muitas organizações, o que mostra a necessidade de que cada microempresa precisa aprender e executar práticas contábeis básicas para garantir que o progresso de seus negócios ocorra sem problemas.

Além de poder melhorar o desempenho empresarial da empresa, as práticas contábeis também representam o resultado das operações de uma empresa, bem como a demonstração da posição financeira. Além disso, segundo Milan et al. (2013), também é importante a execução de estratégias para que haja negociações com fornecedores e para que valores cobrados sejam mais flexíveis, como um acordo que seja favorável para ambos os negócios. Nesse contexto, o procedimento mais necessário é a supervisão criteriosa do fluxo de caixa para análise de possíveis recursos disponíveis, isto é, para que se tenha mais valor adicional na movimentação do caixa.

Falsarella; Jannuzzi e Sugahara (2014) descrevem que o desenvolvimento estratégico é indicado para uma empresa que está com problemas financeiros, pois é considerado como essencial. Assim, deve-se levantar todas as despesas que serão feitas nos próximos tempos para que o gestor possa fazer uma análise macro dos movimentos financeiros futuros.

RC: 101951

Disponível em: https://www.nucleodoconhecimento.com.br/contabilidade/impactosfinanceiros 
Ao definir-se e analisar-se essas despesas, também é possível definir quais delas possuem o maior custo financeiro, pois poderão afetar a organização. Assim, é possível que o gerenciamento dos impactos financeiros possa desenvolver ações de correção que minimizam os gastos desnecessários e até mesmo podem fazer com que sejam reduzidas e cortadas certas despesas. Entende-se que uma microempresa possui inúmeros procedimentos burocráticos e seu impulsionamento e crescimento está relacionado com a qualidade de gestão desse negócio.

Por isso, estudos como o de Gouveia (2014) mostraram a influência da implementação de práticas contábeis nas microempresas, bem como discutem sobre a importância dessas práticas contábeis nas microempresas. Isso se explica, pois mesmo as microempresas realizam funções contábeis diversas, como contabilidade geral, contas a receber, contas a pagar e folha de pagamento.

\subsubsection{CONTABILIDADE GERENCIAL PARA MICRO E PEQUENAS EMPRESAS}

A Contabilidade Gerencial pode ser definida como uma espécie de divisão da ciência contábil. Nela, demonstra-se os esforços superiores de pesquisa em todo o planeta. Apesar de a Contabilidade Gerencial utilizar-se de termos de outras disciplinas, ela se caracteriza por ser uma área contábil autônoma. $O$ tratamento que é dado à informação contábil, com enfoque em planejamento, controle e tomada de decisão, e por ter característica integrativa, é que traz a identidade para a disciplina dentro de um sistema de informação contábil (PADOVEZE, 2010).

De acordo com Atkinson et al. (2011), a Contabilidade Gerencial é o processo que permite identificar, mensurar, relatar e analisar as informações sobre os eventos econômicos da organização.

Como exemplo de informação contábil gerencial, pode-se citar as despesas relacionadas a um departamento operacional da empresa e os custos calculados na fabricação de um produto. Cada vez mais, gestores necessitam de informações 
sobre os segmentos de mercado, produtos e clientes, não somente para controle financeiro, mas também para o controle operacional e de custos. A Contabilidade Gerencial é obtida por meio de todo o processamento de informações, sendo processada e armazenada. Contudo, a Contabilidade Gerencial é capaz de proporcionar o desempenho de atividades, de projetos e de produtos na empresa, assim como discute sobre a situação econômica-financeira a partir de informações claras e precisas (CREPALDI, 2012).

\subsubsection{CONTROLE DE CUSTOS}

Segundo Martins (2011), o custo é o valor pago ao trabalho necessário para a produção de bens ou serviços.

É primordial à administração das empresas o detalhamento de informações de planejamento e controle de custos e lucros para enfrentar os concorrentes que comercializam produtos semelhantes no mercado (SANTOS, 2011).

Dentro deste contexto, o sucesso ou fracasso dependerá da habilidade em gerenciar os custos do negócio para poder criar e sustentar vantagens competitivas (SANTOS, 2005).

Por isso, é de fundamental importância o conhecimento dos custos das empresas, tornando-se, segundo Martins (2010), uma importante arma de controle e decisões gerenciais.

\subsubsection{CONTROLE DE DESPESAS}

Martins (2010) afirma que a despesa é um bem ou serviço abatido de maneira direta ou indireta para a obtenção de receitas.

As despesas operacionais são, segundo ludícibus (2008), contas pagas ou custos para vender produtos e gerenciar administrativamente uma organização, ou seja, são despesas existentes a partir de um esforço. É o quanto custa para realizar uma 
operação, seja de compra, venda, produção ou criação. O controle das despesas e custos, por sua vez, é essencial para manter o equilíbrio entre as receitas, de modo que o resultado se torne positivo, ou seja, visando ao lucro.

\subsubsection{CONTABILIDADE FINANCEIRA PARA AS MICRO E PEQUENAS EMPRESAS}

De acordo com Gouveia (2014), as práticas de gestão econômica e financeira são realizadas nas microempresas. Apesar de terem uma limitação, essas empresas também possuem atividades que precisam de uma gestão e mecanismos econômicos e financeiros. Por isso, a gestão realizada com suporte da contabilidade é essencial para a execução de diversas atividades, como as transações básicas da contabilidade, verificações e controles econômicos e decisões de investimento e financiamento, independentemente do negócio de pequena escala atividade.

Para Assaf Neto (2020), a administração financeira volta-se para quatro funções básicas: planejamento financeiro, controle financeiro, administração de ativos e administração de passivos, sendo que:

1. Planejamento financeiro: busca a evidenciação das necessidades de crescimento da empresa e identificação de possíveis desajustes no futuro;

2. Controle financeiro: acompanha e avalia o desempenho financeiro da empresa, bem como analisa os resultados previstos e realizados e as possíveis medidas de correção;

3. Administração de ativos: busca a melhor estrutura para os investimentos empresariais, bem como mitigar as defasagens que podem ocorrer nas entradas e saídas de recursos, o que pode ser associado à gestão do capital de giro; e

4. Administração de passivos: aquisição de financiamentos, definição de liquidez, redução de custos e risco financeiro. 


\subsubsection{ORÇAMENTO}

Uma ferramenta importante para a gestão gerencial das Micro e Pequenas Empresas é o controle por orçamentos, pois, por meio dele, é possível estabelecer metas a serem atingidas, tanto metas de vendas como de despesas e, consequentemente, de lucro. O orçamento é um instrumento direcional, ou seja, constituído a partir de planos com objetivos específicos, contando, ainda, com datas e unidades monetárias que visam orientar a administração para que possa atingir os objetivos empresariais (FIGUEIREDO; CAGGIANO, 2008).

Para Padoveze (2010 p.517), "[...] Orçamento é a expressão quantitativa de um plano de ação e ajuda a coordenação na execução de um plano emergencial".

Para Schmidt, Santos e Martins (2014, p.178): "[...] o orçamento pode ser definido como a quantificação do planejamento estratégico da empresa, onde é utilizado para fixar metas quantitativas de receita, ganhos, despesas e perdas, bem como fluxos futuros de caixa e patrimônio da empresa".

Tabela 01 - Modelo de orçamento de receita de vendas para micro e pequenas empresas

\begin{tabular}{|l|l|l|l|}
\hline $\begin{array}{l}\text { Categoria } \\
\text { Vendas } \\
\text { Mercadorias }\end{array}$ & Valor planejado $\mathrm{R} \$$ & Valor realizado $\mathrm{R} \$$ & Diferença $\mathrm{R} \$$ \\
\hline & $55.000,00$ & $53.000,00$ & $-2.000,00$ \\
\hline Vendas de Serviços & $26.000,00$ & $33.000,00$ & $7.000,00$ \\
\hline Total & $\mathbf{8 1 . 0 0 0 , 0 0}$ & $\mathbf{8 6 . 0 0 0 , 0 0}$ & $\mathbf{5 . 0 0 0 , 0 0}$ \\
\hline
\end{tabular}

Fonte: Própria (2021) 


\subsubsection{FLUXO DE CAIXA}

De acordo com Tófoli (2008), o fluxo de caixa apresenta-se como uma bússola para as organizações, devido ao seu poder de apontar qual o rumo financeiro deverá ser seguido em determinado momento. Nas várias transações que a empresa faz, como compra, venda, empréstimos e alienações, é necessário que todas as suas dívidas sejam pagas no momento do seu respectivo vencimento. Para isso, deve-se apresentar saldo de caixa disponível no momento da liquidação. A falta de dinheiro em caixa pode propiciar à organização corte no crédito e insuficiência de estoque para atender aos clientes, o que acarreta em alterações nas operações da empresa.

O entendimento de Sá (2008, p. 3) sobre fluxo de caixa é o seguinte: Apresenta-se como uma ferramenta de aferição e interpretação de variações dos saldos do disponível da empresa. É o produto final da integração do contas a receber com as contas a pagar, de tal forma que, quando se comparam as contas recebidas com as contas pagas, tem-se o fluxo de caixa realizado, e quando se comparam as contas a receber com as contas a pagar, tem-se o fluxo de caixa projetado.

Tabela 02 - Modelo de fluxo de caixa para micro e pequenas empresas

\begin{tabular}{|c|c|c|c|}
\hline $\begin{array}{c}\text { FLUXO } \\
\text { DE CAIXA }\end{array}$ & $\begin{array}{c}\text { Seg } \\
\text { 1-nov }\end{array}$ & $\begin{array}{c}\text { Ter } \\
\text { 2-nov }\end{array}$ & $\begin{array}{c}\text { Qua } \\
\text { 3-nov }\end{array}$ \\
\hline TOTAL DE ENTRADAS & $15.000,00$ & $7.000,00$ & $5.500,00$ \\
\hline Vendas Cartão de Crédito & $10.000,00$ & $2.000,00$ & $5.000,00$ \\
\hline Boleto & $5.000,00$ & $5.000,00$ & 500,00 \\
\hline TOTAL DE SAIDAS & $12.500,00$ & $4.500,00$ & $13.500,00$ \\
\hline Fornecedores & $8.000,00$ & $1.500,00$ & $3.000,00$ \\
\hline Salário/Férias/Rescisão & $3.500,00$ & - & $9.000,00$ \\
\hline Outras Despesas & $1.000,00$ & $3.000,00$ & $1.500,00$ \\
\hline SALDO OPERACIONAL & $2.500,00$ & $2.500,00$ & $-8.000,00$ \\
\hline SALDO INICIAL & $1.500,00$ & $4.000,00$ & $6.500,00$ \\
\hline SALDO FINAL & $4.000,00$ & $6.500,00$ & $-1.500,00$ \\
\hline
\end{tabular}

Fonte: Site boa vista tecnologia (2021).

RC: 101951

Disponível em: https://www.nucleodoconhecimento.com.br/contabilidade/impactosfinanceiros 
A partir do gerenciamento do fluxo de caixa é possível adquirir a capacidade que permite analisar e diagnosticar problemas futuros que poderão afetar o desempenho operacional e financeiro da empresa, pois mesmo que no presente se demonstrem resultados econômicos positivos à empresa, esta pode ir à falência por apresentar uma deficiência em seu caixa decorrente às altas dívidas a serem pagas a terceiros, elevados investimentos, perdas e outros fatores que afetam seu balanço (BIAZZI, 2005).

\subsection{GESTÃO EMPRESARIAL NAS MICRO E PEQUENAS EMPRESAS}

Segundo Cardoso; Silva e Moreira (2019), a gestão empresarial corresponde ao direcionamento das operações de uma organização. Esse contexto envolve o desenvolvimento de ideias, incluindo finanças e economia, as funções dos recursos humanos e como aplicar a análise estatística para melhor orientar os planos de longo prazo de uma empresa. No entanto, quanto maior o tamanho de uma empresa, isto é, quanto mais ela cresce, maiores serão as responsabilidades implicadas a cada função, sendo que as funções divergem em áreas mais especializadas. As empresas tendem a contar com os gerentes de negócios para lidarem com questões como gerenciamento de equipes, bem como para que possam analisar melhor as questões interpessoais. De acordo com Morais e Barreto Júnior (2019), a gestão empresarial objetiva atender os aspectos humanos de uma empresa.

Por isso, a contabilidade pode ser usada como uma ferramenta de gestão, pois envolve a gestão da saúde financeira da empresa, uma vez que, quando uma empresa é ágil nos seus controles financeiros, há uma facilidade em administrar de uma forma mais eficaz os seus processos. Garcez et al. (2013) enfatizam que essa prática se refere a fazer escolhas entre atitudes alternativas de ação, o que também pode incluir a inação. Embora possa-se argumentar que gerenciamento é a tomada de decisão, metade das decisões tomadas pelos gerentes dentro das empresas podem fracassar. Portanto, segundo Lacerda et al. (2013), é necessário aumentar a eficácia na tomada de decisões por ser uma parte importante para maximizar a 
eficácia na gestão empresarial, pois os indivíduos, em todas as organizações, usam as informações que reúnem para tomarem diversas decisões.

Essas decisões podem afetar diversas áreas das empresas e podem mudar o desenvolvimento da organização.

\section{MATERIAIS E MÉTODOS}

De acordo com Máttar Neto (2017), a seção de materiais e métodos corresponde a etapa da pesquisa que descreve os detalhes da metodologia utilizada no trabalho. Corresponde ao plano escolhido para a descrição do que foi utilizado para o desenvolvimento e aponta-se, também, de que forma foi executado.

\subsection{PROCEDIMENTOS METODOLÓGICOS}

De acordo com Marconi e Lakatos (2015), os instrumentos metodológicos são as ferramentas que devem guiar o percurso a ser seguido na composição do artigo. Segundo Severino (2017), os procedimentos metodológicos são desenvolvidos para alcançarem os objetivos estabelecidos na pesquisa, sendo definidas, também, as técnicas usadas para identificar, selecionar, processar e analisar informações sobre o desenvolvimento do estudo. Nesse sentido, nesta seção, o presente estudo apresenta os procedimentos metodológicos utilizados para o desenvolvimento dessa pesquisa.

\subsubsection{QUANTO À NATUREZA}

Segundo Nunes; Nascimento e Alencar (2016), a natureza de uma pesquisa pode ser definida como aplicada e básica. Para Máttar Neto (2017), a natureza aplicada visa encontrar uma solução para um problema imediato enfrentado por uma sociedade, ou, ainda, por uma organização industrial e/ou empresarial, enquanto a pesquisa básica se preocupa, principalmente, com generalizações e com a formulação de uma teoria. Diante disso, o presente estudo pôde ser classificado 
como pesquisa de natureza aplicada, pois foi realizado com a finalidade de encontrar a solução para um problema específico.

\subsubsection{QUANTO AOS FINS}

Segundo Severino (2017), as pesquisas descritivas visam obter informações suficientes sobre o problema de pesquisa: o quê, como, quando e onde as respostas serão encontradas, razão pela qual a pesquisa descritiva é um tipo importante de pesquisa. De acordo com Köche (2016), esse método de pesquisa trabalha com um problema com pouca ou nenhuma informação relevante e desenvolve uma descrição a partir de métodos de pesquisa qualitativos ou quantitativos. Por isso, este artigo foi classificado com fins descritivos, pois foi descrito com precisão, baseado em um problema de pesquisa pré-estabelecido.

\subsubsection{QUANTO AOS MEIOS}

Segundo Severino (2017), o meio de pesquisa bibliográfico é uma pesquisa e avaliação da literatura disponível em seu determinado assunto ou área de tópico escolhido. Para Libório e Terra (2015), esse meio pode ser utilizado de forma conjugado com outros meios, sendo usado como forma de embasar a pesquisa de forma científica. Por isso, esse artigo se caracterizou como meio de pesquisa bibliográfico, pois o desenvolvimento foi determinado pela coleta feita em estudos já realizados, como artigos, livros e publicações de órgãos oficiais.

\section{CONSIDERAÇÕES FINAIS}

A pandemia provocada pela COVID-19 trouxe mudanças significativas para as vidas das pessoas e atividades comerciais em nível regional, nacional e global. Adotou-se uma série de medidas de contenção para conter a propagação do vírus. Embora essas medidas possam ter contribuído para o controle bem-sucedido do vírus, essas restrições afetaram fortemente as operações comerciais.

RC: 101951

Disponível em: https://www.nucleodoconhecimento.com.br/contabilidade/impactosfinanceiros 
A partir dos estudos e dados analisadas, foi possível concluir que as empresas tiveram que buscar mecanismos que pudessem proporcionar a garantia de seu funcionamento.

Neste contexto, os resultados apresentados nesta pesquisa demonstraram que as medidas de bloqueio reduziram a atividade empresarial em mais da metade. As micro e pequenas empresas experimentaram um declínio maior na atividade empresarial em comparação com as empresas de médio e grande porte. Uma descoberta que não surpreende, pois, grande parte das micro e pequenas empresas do país interromperam suas operações e muitas declararam que os seus pequenos negócios não conseguiriam funcionar de maneira online. Essas medidas preventivas causaram um impacto financeiro negativo nessas empresas, sendo que algumas dessas não estavam preparadas e nem possuíam formas adequadas para gerenciarem tais situações.

Em resposta à questão da pesquisa: Como a contabilidade pode auxiliar na gestão financeira das micro e pequenas empresas perante à crise provocada pela pandemia da COVID-19? Constatou-se que a contabilidade possui ferramentas úteis ao processo gerencial e financeiro, podendo auxiliar no controle de custos e despesas e no controle financeiro por meio do orçamento e do fluxo de caixa, mesmo tratando-se de micro e pequenas empresas. Nesse contexto, os objetivos descritos nesse estudo foram alcançados, visto que a pesquisa apontou os tipos de ferramentas contábeis necessárias à gestão financeira das micro e pequenas empresas, bem como demonstrou-se as formas de controle e gerenciamento financeiro indicadas não apenas para os momentos de crise, mas também para o futuro do empreendimento e destacou os impactos que a crise provocada pela pandemia da COVID-19 gerou nas questões financeiras e gerenciais das micro e pequenas empresas.

Sendo assim, espera-se que esta pesquisa sirva de incentivo a outros estudiosos e profissionais de contabilidade que buscam se manter atualizados. 


\section{REFERÊNCIAS}

ALMEIDA, J. Fundamentos de Contabilidade para os Negócios: introdução à contabilidade. São Paulo: Elsevier Brasil, 2016.

ARAÚJO, I. da. P. S. Introdução à contabilidade. São Paulo: Saraiva Educação SA, 2017.

ASSAF NETO, A. Finanças corporativas e valor. 8a ed. São Paulo: Atlas, 2020

ATKINSON, A. et al. Contabilidade gerencial. Tradução: André Olímpio Mosselman

Du Chenoy Castro, Revisão Técnica Rubens Famá. 3ae ed. São Paulo: Atlas, 2011.

BANTERLI, F. R.; MANOLESCU, F. M. K. As micro e pequenas empresas no Brasil e a sua importância para o desenvolvimento do país. Centro, v. 9, p. 8, 2017.

BERNARDES, J. R.; SOUSA, B. L. S. de.; LIMA, T. C. F. Os impactos financeiros da Covid-19 nos negócios. Revista da FAESF, v. 4, 2020.

BIAZZI, Juceli Antonio. Aplicação do fluxo de caixa como ferramenta de gestão financeira às instituições de ensino superior: um estudo de caso. 2005. $171 \mathrm{f}$. Dissertação (Mestrado em Ciências Contábeis) - Universidade Regional de Blumenau, Blumenau, SC, 2005.

PINHEIRO, K. Fluxo de caixa: tudo o que você precisa saber para ter sucesso e potencializar seu negócio. 2019.2 Disponível em: https://boavistatecnologia.com.br/blog/fluxo-de-caixa/. Acesso em: 23 out. 2021.

BRASIL. Lei Complementar no 123, de 14 de dezembro de 2006. Institui o Estatuto Nacional da Microempresa e da Empresa de Pequeno Porte; altera dispositivos das Leis no 8.212 e 8.213, ambas de 24 de julho de 1991, da Consolidação das Leis do Trabalho - CLT, aprovada pelo Decreto-Lei no 5.452, de 10 de maio de 1943, da Lei no 10.189 , de 14 de fevereiro de 2001, da Lei Complementar no 63, de 11 de janeiro 
de 1990; e revoga as Leis no 9.317, de 5 de dezembro de 1996, e 9.841, de 5 de outubro de 1999.

CREPALDI, S. A. Contabilidade gerencial: teoria e prática. 6ª ed. São Paulo: Atlas, 2012.

FALSARELLA, O. M.; JANNUZZI, C. A. S. C.; SUGAHARA, C. R. Planejamento estratégico empresarial: proposta de um sistema de inteligência organizacional e competitiva. RDBCI: Revista Digital de Biblioteconomia e Ciência da Informação, v. 12, n. 2, p. 193-216, 2014.

FIGUEIREDO, S.; CAGGIANO, P. C. Controladoria: Teoria e prática. 4aa ed. São Paulo: Atlas, 2008.

FREY, I. A.; FREY, M. R. O uso de informações contábeis na pequena empresa. Pensar contábil, v. 6, n. 19, 2015.

GOUVEIA, H. M. N. A utilidade da contabilidade para as microempresas. 2014. 144f. Dissertação (Mestrado em Contabilidade) - Universidade do Algarve, Faro, Portugal, 2014.

IBGE - Instituto Brasileiro de Geografia e Estatística. As Micro e Pequenas Empresas Comerciais e de Serviços no Brasil. 2011. Disponível em: https://www.ibge.gov.br/estatisticas/economicas/outras-estatisticaseconomicas/2048-np-as-micro-e-pequenas-empresas-comerciais-e-de-servicos-nobrasil.html. Acesso em: 1 out. 2021.

IBGE - Instituto Brasileiro de Geografia e Estatística. As Micro e Pequenas Empresas Comerciais e de Serviços no Brasil. 2020. Disponível em: https://www.ibge.gov.br/estatisticas/economicas/outras-estatisticaseconomicas/2048-np-as-micro-e-pequenas-empresas-comerciais-e-de-servicos-nobrasil.html. Acesso em: 1 set. 2021. 
IUDíCIBUS, S.; MARTINS, E.; GELBCKE, E. R. Manual de Contabilidade das Sociedades por Ações (Aplicável às Demais Sociedades). São Paulo: Atlas S.A., 2007. v. 8.

JACOMETE, B. de. O. O papel das micro e pequenas empresas na economia brasileira. Revista Eletrônica de Debates em Economia, v. 7, n. 1, 2019.

JESUS, N. D.; MARINHO, G. Microempresas brasileiras: entendendo seu papel socioeconômico. REMIPE-Revista de Micro e Pequenas Empresas e Empreendedorismo da Fatec Osasco, v. 5, n. 1, p. 165-177, 2019.

KÖCHE, J. C. Fundamentos de metodologia científica. São Paulo: Editora Vozes, 2016.

LACERDA, R. M. et al. A importância da informação contábil no processo de tomada de decisão nas micro e pequenas empresas. Revista Contemporânea de Contabilidade, v. 10, n. 19, p. 119-140, 2013.

LIBÓRIO, D.; TERRA, L. Metodologia científica. Baltimore, Maryland: Editora Laureate International Universities, 2015.

MARCELINO, J. A.; REZENDE, A.; MIYAJI, M. Impactos iniciais da covid-19 nas micro e pequenas empresas do estado do Paraná-Brasil. Boletim de Conjuntura (BOCA), v. 2, n. 5, p. 101-112, 2020.

MARCONI, M. de. A.; LAKATOS, E. M. Metodologia científica: ciência e conhecimento científico, métodos científicos, teoria, hipóteses e variáveis, metodologia jurídica. In: MARCONI, M. de. A.; LAKATOS, E. M. Metodologia científica: ciência e conhecimento científico, métodos científicos, teoria, hipóteses e variáveis, metodologia jurídica. São Paulo: Atlas, 2015. p. 314-314. 
MORAIS, R. A. C; BARRETO JÚNIOR, A. C. A Importância da Contabilidade Gerencial para Microempresas e Empresas de Pequeno Porte. Revista de Psicologia, v. 13, n. 43, p. 903-921, 2019.

MARTINS, E. Contabilidade de custos. 10ªe ed. São Paulo: Atlas, 2010.

NASCIMENTO, J. P. S.; GOMES, D. W. R.; OLIVEIRA, O. V. O controle interno nas microempresas e empresas de pequeno porte. Revista Expressão Católica, v. 9, n. 1,2020

MÁTTAR NETO, J. A. Metodologia científica na era da informática. São Paulo: Saraiva Educação SA, 2017.

NUNES, G. C.; NASCIMENTO, M. C. D.; ALENCAR, M. A. C. de. Pesquisa científica: conceitos básicos. Revista de Psicologia, v. 10, n. 29, p. 144-151, 2016.

PADOVEZE, C. L. Contabilidade gerencial: um enfoque em sistema de informação contábil. 7ª̣ ed. São Paulo: Atlas 2010.

PAULANI, L.; BOBIK, M. A nova contabilidade social: uma introdução à macroeconomia. São Paulo: Saraiva Educação SA, 2020.

PESSÔA, L. C.; COSTA, G. da.; MACCARI, E. A. As micro e pequenas empresas, o Simples Nacional e o problema dos créditos de ICMS. Revista Direito GV, v. 12, p. 345-363, 2016.

RENDÓN, O. H. P. Modelo del Plan de Negocios: para micro y pequeña empresa. São Paulo: Grupo Editorial Pátria, 2014.

RIBEIRO, O. M. Contabilidade intermediária. São Paulo: Saraiva Educação SA, 2017.

SÁ, C. A. Fluxo de caixa: a visão da Tesouraria e da Controladoria. $3^{\underline{a}}$ ed. São Paulo, Atlas, 2008. 
SANTOS J. J. Análise de custos. 4ª ed. São Paulo: Atlas, 2005.

SANTOS J. J. Contabilidade e análise de custos. 6ª ed. São Paulo: Atlas, 2011.

SANTOS, J. E.; OLIVEIRA, E. C. de. Empreendedorismo e incentivos governamentais para a sobrevivência de empresas no período da pandemia do coronavírus. Cadernos de Gestão e Empreendedorismo, v. 9, n. 1, p. 60-70, 2021.

SANTOS, V. dos.; DOROW, D. R.; BEUREN, I. M. Práticas gerenciais de micro e pequenas empresas. Revista Ambiente Contábil, v. 8, n. 1, p. 153-186, 2016.

SEBRAE. Lei geral das micro e pequenas empresas. Site do Sebrae. 2021. Disponível em: https://www.sebrae.com.br/sites/PortalSebrae/artigos/entenda-asdiferencas-entre-microempresa-pequena-empresa-emei,03f5438af1c92410VgnVCM100000b272010aRCRD. Acesso em: 22 ago. 2021.

SEBRAE. Painel de empresas. Site do Sebrae. 2020. Disponível em: https://datasebrae.com.br/totaldeempresas-11-05-2020/. Acesso em: 4 set. 2021.

SEVERINO, A. J. Metodologia do trabalho científico. São Paulo: Cortez, 2017.

SILVA, D. de. C. M. et al. GESTÃO DA SEGURANÇA DA INFORMAÇÃO EM UMA MICROEMPRESA. RECIMA - Revista Científica Multidisciplinar, v. 2, n. 6, p. e26441-e26441, 2021.

SILVESTRE, G. F. Novos problemas, antigas soluções: o amplo significado da cláusula rebus sic stantibus e a renegociação, a suspensão e a conservação dos contratos cíveis e mercantis. Civilistica.com, v. 9, n. 2, p. 1-26, 2020.

SHMIDT, P.; SANTOS, J. L. dos.; MARTINS, M. A. dos. S. Manual de controladoria. $1^{a}$ ed. São Paulo: Campos Elísios, 2014. 
SQUEFF, T. C.; D'AQUINO, L. S.; TARGA, M. L. B. O império das medidas provisórias e a proteção do mercado no Brasil em tempos de pandemia. Revista Chilena de Derecho y Ciencia Política, v. 11, n. 2, p. 9-43, 2020.

TÓFOLI, I. Administração Financeira Empresarial - uma tratativa prática. Campinas: Arte Brasil Editora/Unisalesiano, 2008.

Enviado: Outubro, 2021.

Aprovado: Novembro, 2021. 